\title{
Title: Atypical severe progressive perioral ulceration due to herpes simplex virus on the background of undiagnosed HIV/AIDS
}

Authors: Howard, $\mathrm{M}^{1}$ (MBBS (Hons), BPharm (Hons)), Poon, F ${ }^{2}$ (MBBS, MHSc), Milne, $\mathrm{O}^{2}$ (MBBS,

BVSc, FACD), Kelmann, $\mathrm{A}^{3}$ (MBBS) Chong, $\mathrm{AH}^{4,5}$ (MBBS, M.Med, FACD)

Short running title: Atypical perioral ulceration from HSV

Affiliations:

1. Victorian Melanoma Service, Alfred Hospital, Melbourne, Victoria, Australia

2. Department of Dermatology, Monash Health, Clayton, Victoria, Australia

3. Department of Pathology, Monash Health, Clayton, Victoria, Australia

4. Skin \& Cancer Foundation Inc., Melbourne, VIC, Australia

5. Department of Medicine, St Vincent's Hospital, University of Melbourne, Melbourne, VIC, Australia

Corresponding author: Matthew Howard, Matthew.david.howard@gmail.com

Mob: +61435117162

Postal address: 55 Commercial Rd, Melbourne, Victoria, Australia, 3004

Funding sources: none

Conflict of interest: The authors have no conflicts of interest to declare

This manuscript nor any of its contents have been presented by the authors

Word count: 1101

Reference count: 10

Figure count: 3

This is the author manuscript accepted for publication and has undergone full peer review but has not been through the copyediting, typesetting, pagination and proofreading process, which may lead to differences between this version and the Version of Record. Please cite this article as doi: 10.1111/AJD.13111

This article is protected by copyright. All rights reserved 
Key Words: herpes simplex virus, human immunodeficiency virus, HIV, HSV, ulceration

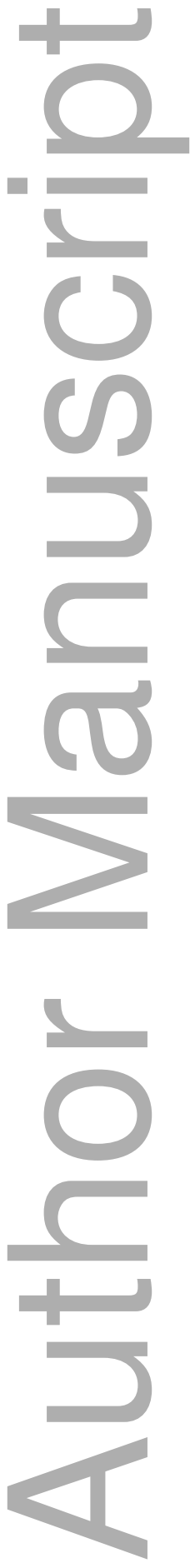

This article is protected by copyright. All rights reserved 
DR. MATTHEW DAVID HOWARD (Orcid ID : 0000-0002-7988-7577)

DR. FLORA POON (Orcid ID : 0000-0001-8060-7360)

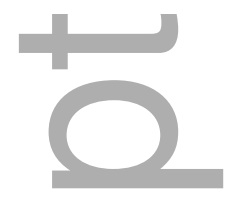

Article type : Brief Reports

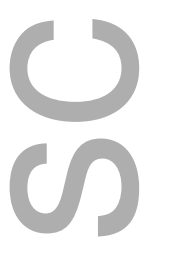

Atypical severe progressive perioral ulceration due to herpes simplex virus on the background of undiagnosed HIV/AIDS

\section{Abstract}

Perioral ulcerative plaques have a broad list of differential diagnoses. We describe an unusual presentation of chronic progressive perioral ulceration due to Herpes simplex type 1 on a background of undiagnosed human immunodeficiency virus infection with acquired immunodeficiency syndrome. Whilst chronic mucocutaneous HSV is an AIDS-defining condition with both HSV-1 and - 2 implicated, typical reported cases describe vesicular eruptions rather than perioral ulcerative plaques. This case highlights that common infections may present atypically in immunocompromised individuals and may be a clue to underlying systemic illness.

\section{Abbreviations}

HSV- herpes simplex virus

PCR- polymerase chain reaction

CD- cluster of differentiation

HIV- human immunodeficiency virus

AIDS- acquired immunodeficiency syndrome 


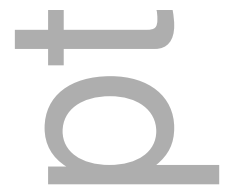

$\square$

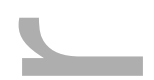

Introduction

Perioral ulcerative plaques have many differential diagnoses. In this case, we describe an unusual presentation of chronic progressive perioral ulceration due to the Herpes simplex type 1 virus. A prompt systemic work-up was conducted to assess any predisposing factors to this severe HSV manifestation, which resulted in a new diagnosis of HIV with significant acquired immunodeficiency. This case report highlights that common infections may present atypically in immunocompromised individuals and may be a clue to underlying systemic illness. Prompt multidisciplinary treatment is often required to prevent further progression and sequelae.

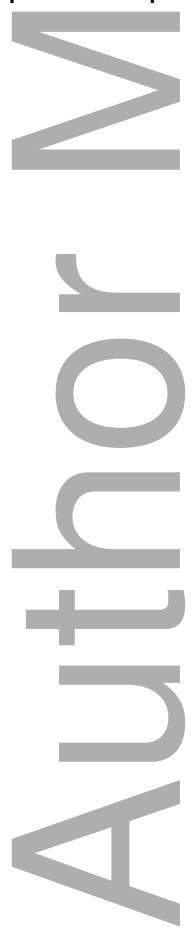

This article is protected by copyright. All rights reserved 


\section{Case Report}

We report a case of 43 year old Sri Lankan male refugee, who presented with a five month history of enlarging ulcerative plaques affecting his right lateral commissure lip extending into his cheek. He also had an eroded area with a papulovesicular edge affecting his left mastoid process (Figure 1). There was no involvement of his internal oral mucosa. There was no clinical lymphadenopathy. The patient had a background history of perianal fissures and fistulas. Previous surgery included a sigmoidoscopy and perianal fissure and abscess debridement two years prior and a seton insertion five months prior. There was no past personal, nor family history of auto-inflammatory disorders. The last reported travel overseas to Sri Lanka was one year prior. Further systems review revealed weight loss but no other constitutional symptoms. Previous biopsies of the lip ulcer yielded granulation tissue only. Topical hydrozole and mupirocin ointment was initiated by his local family doctor but were of no benefit.

The differential diagnosis was broad for this case and included both an infective and autoinflammatory processes. Atypical infections including leishmaniasis, mycobacteria or typical infections including a viral infection such as herpes simplex virus (HSV) with concomitant immunosuppression should be included in the differential along with inflammatory conditions such as extraintestinal Crohn's disease in view of the perianal fissures, pyoderma gangrenosum and unusual manifestation of auto-inflammatory connective tissue diseases such as Behcet's disease.

Histopathology of repeat biopsies revealed a necrotic epidermis with heavy neutrophil infiltrate and multinucleated keratinocytes (Figure 2). Specific immunohistochemistry was positive for the HSV-1 virus within epithelial cells. Wound swabs for microscopy, culture, sensitivity and HSV polymerase chain reaction (PCR) were taken which showed mixed skin flora, no polymorphs and HSV-1 specific positivity respectively. Herpes simplex type 2 PCR was negative. Leishmania PCR was negative on tissue culture of the punch biopsies in addition to serology. Further Full blood examination revealed a lymphocytopenia $\left(0.33 \times 10^{9} / \mathrm{L}\right.$, normal $\left.1.0-4.0 \times 10^{9} / \mathrm{L}\right)$ with subsequent HIV testing performed in view of the atypical HSV ulceration found to be positive with a viral load of 4394463 copies $/ \mathrm{mL}$. There was a significant decreased CD3/CD4 ratio of $2 \%$ (normal: $31-59 \%$ ) and absolute CD4 count of 6 (389-1569).

Dual clinicopathologic diagnoses of severe HSV-1 ulceration in addition to a new diagnosis of HIV were made. Together with Infectious diseases specialists, the patient was commenced on antiretroviral therapy (emtricitabine-tenofovir alafenamide combination tablet (Descovy ${ }^{\circledR}$ ) 200/25mg daily and dolutegravir 50mg daily) along with famciclovir 500mg twice daily for treatment of HSV. Additional antimicrobial prophylaxes commenced by the infectious disease team: 
trimethoprim/sulfamethoxazole 160/800mg three times per week for Pneumocystis jirovecii prophylaxis, benzylpenicillin 1.8g intramuscular single dose given the patient had prior positive treponemal testing, thiamine $100 \mathrm{mg}$ daily and moxifloxacin $400 \mathrm{mg}$ daily for prophylaxis of hospital acquired pneumonia and treatment of potential mycobacterium tuberculosis given severe acquire immunodeficiency and fevers that later developed during the inpatient stay. Serial blood cultures, bronchial washings, sputum cultures and Quantiferon gold testing were negative for $M$. tuberculosis infection and other pathogens. After two weeks of antiviral therapy, both ulcers healed with significant post-inflammatory hypopigmentation (Figure 3) and the HIV viral load responded to antiretroviral therapy (less than 40 copies $/ \mathrm{mL}$ ). After this period, famciclovir was replaced with valganciclovir for cytomegalovirus prophylaxis $900 \mathrm{mg}$ twice daily.

The patient is currently receiving close monitoring whilst on retroviral treatment and ongoing contact tracing and psychosocial patient-family counselling is underway.

\section{Discussion}

This case highlights that atypical ulcerative HSV infection can present on the background of undiagnosed immunosuppression, where it is a recognised AIDS defining illness ${ }^{1}$, although in our case, our patient met the criteria for AIDS on low CD4 count. With directed investigations towards potential predisposing factors towards HSV, prompt multidisciplinary treatment is crucial for patients.

Patients with immunodeficiency are at higher risk of developing a severe HSV infection with recurrent infection often more extensive, protracted, symptomatic and aggressive in nature ${ }^{2,3}$. Unlike its well-recognised vesicular eruption in the immunocompetent population ${ }^{2}$, HSV infection presents atypically in the immunocompromised ${ }^{3}$. Knife-like ulceration (a distinctive presentation of linear erosive herpes simplex virus infection in intertriginous areas) ${ }^{4}$, primary herpetic gingivostomatitis ${ }^{3}$, conjunctivitis ${ }^{2}$, severe herpetic whitlow ${ }^{1}$, persistent irregular ulcerative plaques ${ }^{1-}$ ${ }^{3}$, pseudovesicular erythematous papules coalescing into plaques ${ }^{1}$, Grossman's geometric glossitis (tender dorsal tongue fissures in a longitudinal, cross-hatched, or branched pattern) ${ }^{5}$, hypertrophic, condylomatous or tumour like exophytic masses ${ }^{3,6}$ and large chronic eroded lesions mimicking 
pemphigus vulgaris and bullous pemphigoid have all been reported ${ }^{7}$. Fatal systemic infections due to disseminated infection without orofacial or genital lesions are possible in the immunocompromised population ${ }^{3}$, with recurrent severe HSV-1 infections a major cause of morbidity and mortality in immunocompromised patients prior to the availability of current antiviral therapies ${ }^{2}$. Cellular immunodeficiencies that are associated with atypical HSV manifestations include: primary congenital cellular immunodeficiencies ${ }^{8}$, acute and chronic leukaemias ${ }^{6}$, Good's $^{\prime}$ syndrome ${ }^{9}$, iatrogenic immunosuppression of autoimmune conditions ${ }^{7}$, organ transplant recipients ${ }^{6}$ and also through chemotherapy treatment of malignancy ${ }^{6}$ as well as AIDS ${ }^{1}$.

The punched out peripheral monomorphic papulovesicles and location on the lateral lip commissure provided clinical clues towards a diagnosis of an atypical HSV infection. Negative tissue biopsies/immunofluorescence for diagnosis of HSV is possible depending on whether active infection is present in the tissue sampled ${ }^{10}$. Despite reports of increased resistance, our patient responded quickly to anti HSV treatment with famiciclovir. This may have been assisted by improved adaptive immunity due to commencement of antiretroviral combination therapy, which resulted in quick suppression of the HIV viral load. Involvements of the infectious disease team were vital to our patient's treatment in order to co-ordinate antiretroviral therapy and commence appropriate antimicrobial therapies before further opportunistic infections developed.

HSV-1 is a common cause of mucocutaneous lesions in the general population with high infection and seroprevalence rates ${ }^{2}$. As such, although our patient had potential for atypical infections due to a prior history of living in endemic areas and also for inflammatory bowel disease due to concurrent perianal fistula; common pathology should still be considered. In our patient, the severe acquired immunosuppression from concurrent HIV infection likely accounted for the atypical presentation, the lack of healing and chronic progression of HSV related ulceration ${ }^{3}$. It is important that amidst the plethora of opportunistic infections and manifestations of HIV/AIDS that the clinician remains aware of the potential for atypical herpes simplex infection.

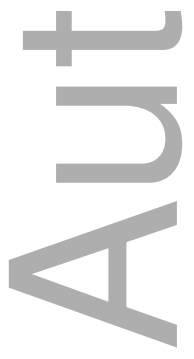

This article is protected by copyright. All rights reserved 


\section{References}

1. Langtry J, Ostlere L, Hawkins D, Staughton R. The difficulty in diagnosis of cutaneous herpes simplex virus infection in patients with AIDS. Clin Exp Dermatol. 1994;19(3):224-6.

2. Arduino P, Porter S. Herpes Simplex Virus Type 1 infection: overview on relevant clinicopathological features. J Oral Pathol Med. 2008;37(2):107-21.

3. Fatahzadeh M, Schwartz R. Human herpes simplex virus infections: epidemiology, pathogenesis, symptomatology, diagnosis, and management. J Am Acad Dermatol. 2007;57(5):737-

63.

4. Lieb J, Brisman S, Herman S, Macgregor J, Grossman M. Linear erosive herpes simplex virus infection in immunocompromised patients: the "knife-cut sign". Clin Infect Dis. 2008;47(11):1440-1. 5. Grossman M, Stevens A, Cohen P. Brief report: herpetic geometric glossitis. N Engl J Med. 1993;329(25):1859-60.

6. Ogawa Y, Higuchi T, Koyamada R, Arai S, Okada S. Hypertrophic Herpes Simplex Virus Type 1 Infection in a Patient With Acute Myeloid Leukemia. J Hematol. 2017;2-3(68-71).

7. Lecluse A, Bruijnzeel-Koomen C. Herpes Simplex Virus Infection Mimicking Bullous Disease in an Immunocompromised Patient. Case Rep Dermatol. 2010;2(2):99-102.

8. Raje N, Dinakar C. Overview of Immunodeficiency Disorders. Immunol Allergy Clin North Am. 2015;35(4):599-623.

9. Kelleher P, Misbah SA. What is Good's syndrome? Immunological abnormalities in patients with thymoma. J Clin Pathol. 2003;56(1):12-6.

10. LeGoff J, Péré H, Bélec L. Diagnosis of genital herpes simplex virus infection in the clinical laboratory. Virol J. 2014;11:83.

This article is protected by copyright. All rights reserved 


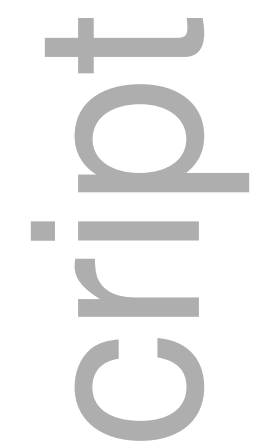

\section{Figure legends}

Figure 1: large area of ulceration affecting the right lateral commissure lip and smaller ulcerated plaque affecting the left mastoid process prior to referral

Figure 2: Left image arrow pointing to HSV inclusion in necrotic keratinocyte. Other necrotic keratinocytes, macrophages and part of some foreign material are also present (haematoxylin and eosin, $\mathrm{HE}, \mathrm{x} 400$ ). Right image: Arrow points to positive immunohistochemical assay for HSV (Herpes Simplex Virus type 1 immunohistochemistry, $\mathrm{x} 400)$.

Figure 3: healed ulcerative plaques with hypo and hyper pigmentation on the right lateral commissure lip and left mastoid process after two weeks of antiviral and antiretroviral therapy.

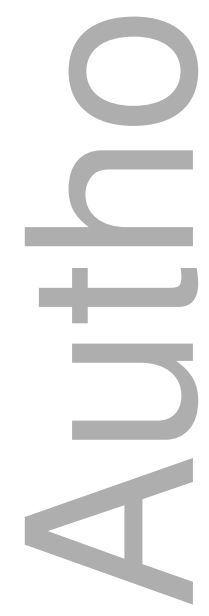

This article is protected by copyright. All rights reserved 

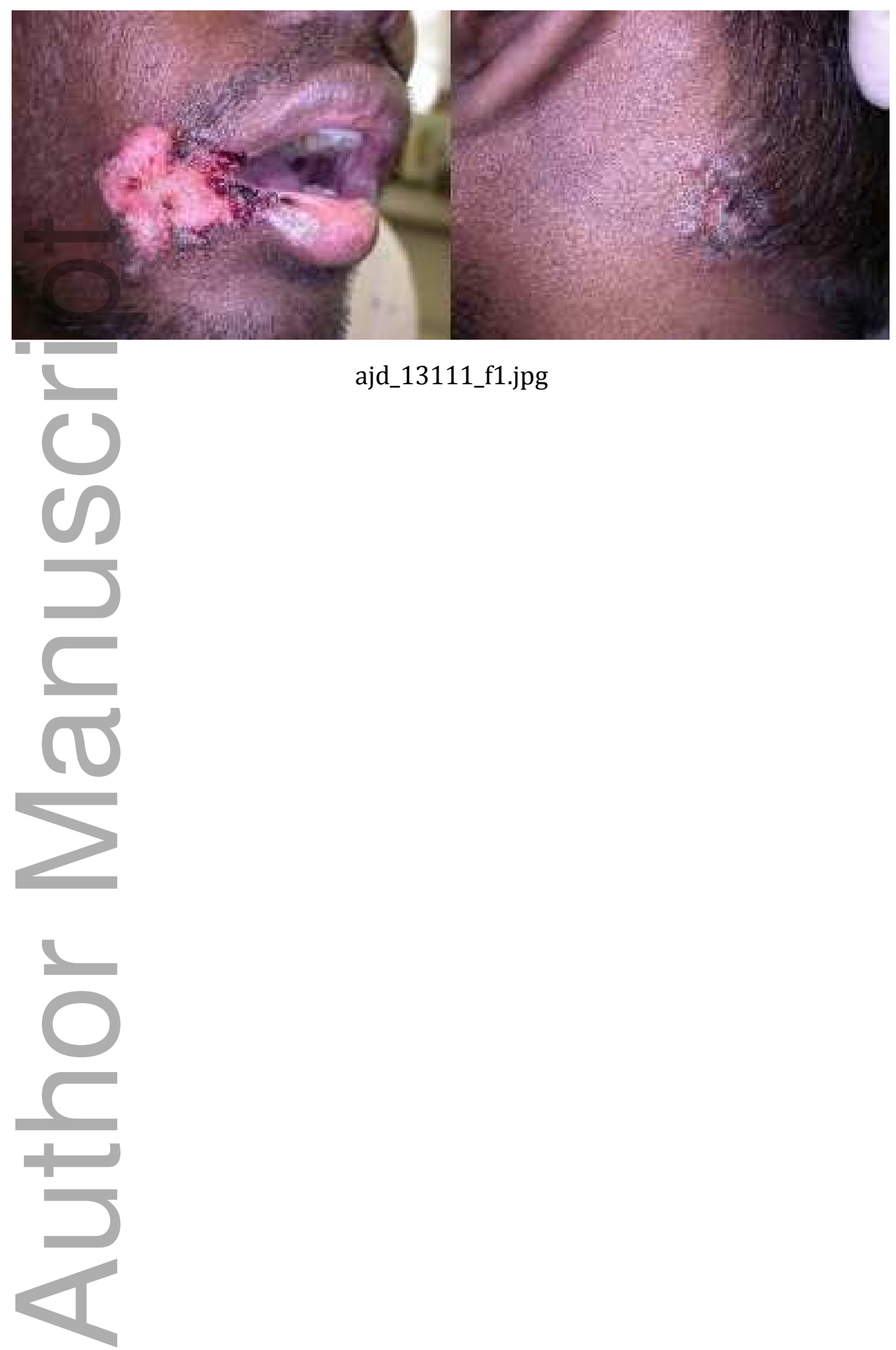

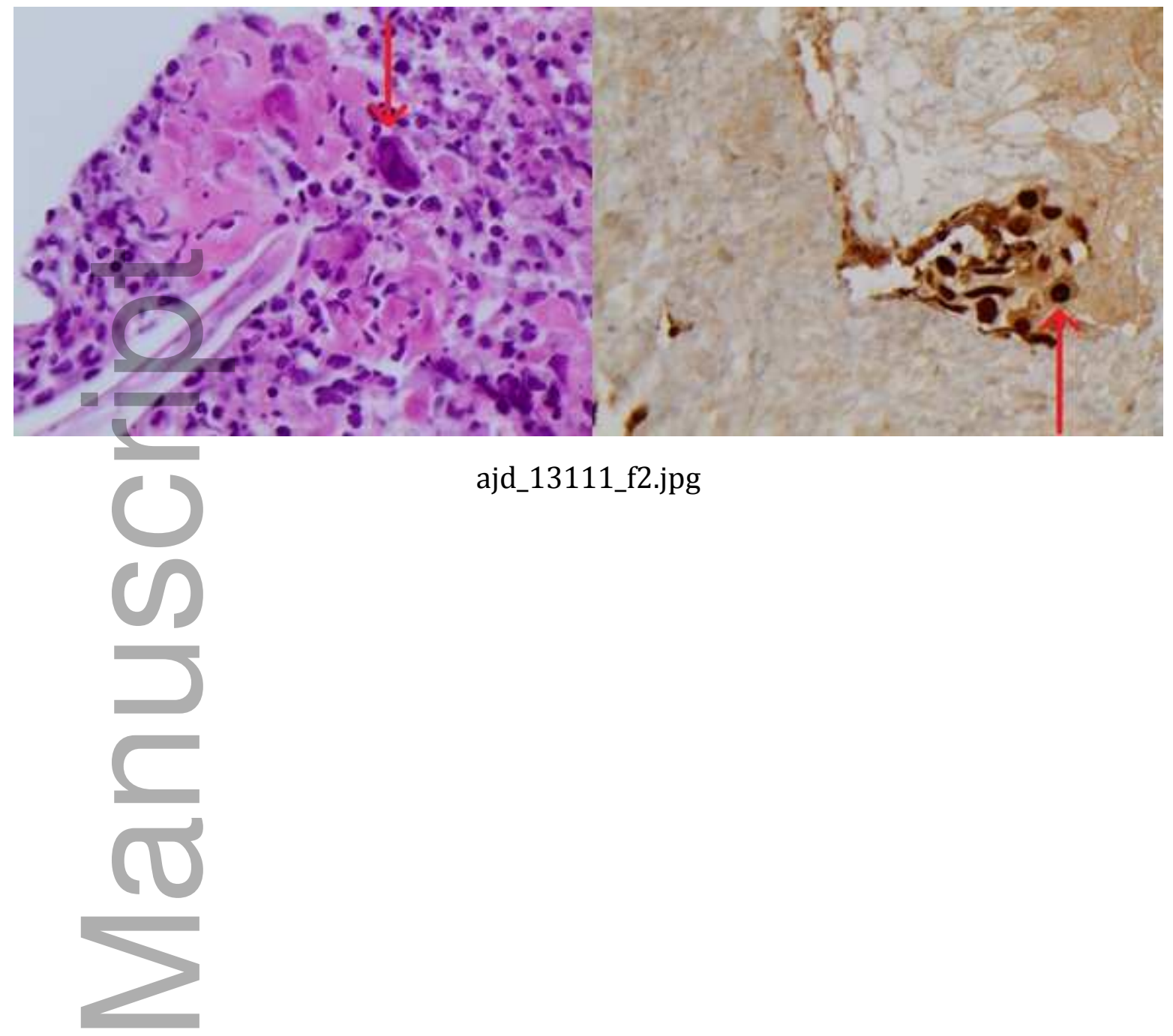

ajd_13111_f2.jpg

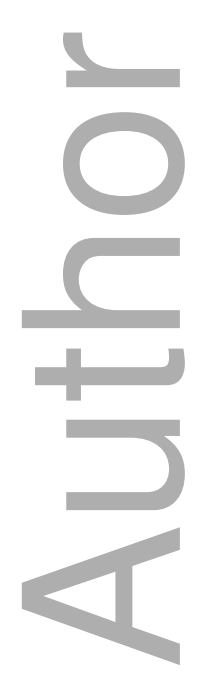

This article is protected by copyright. All rights reserved 


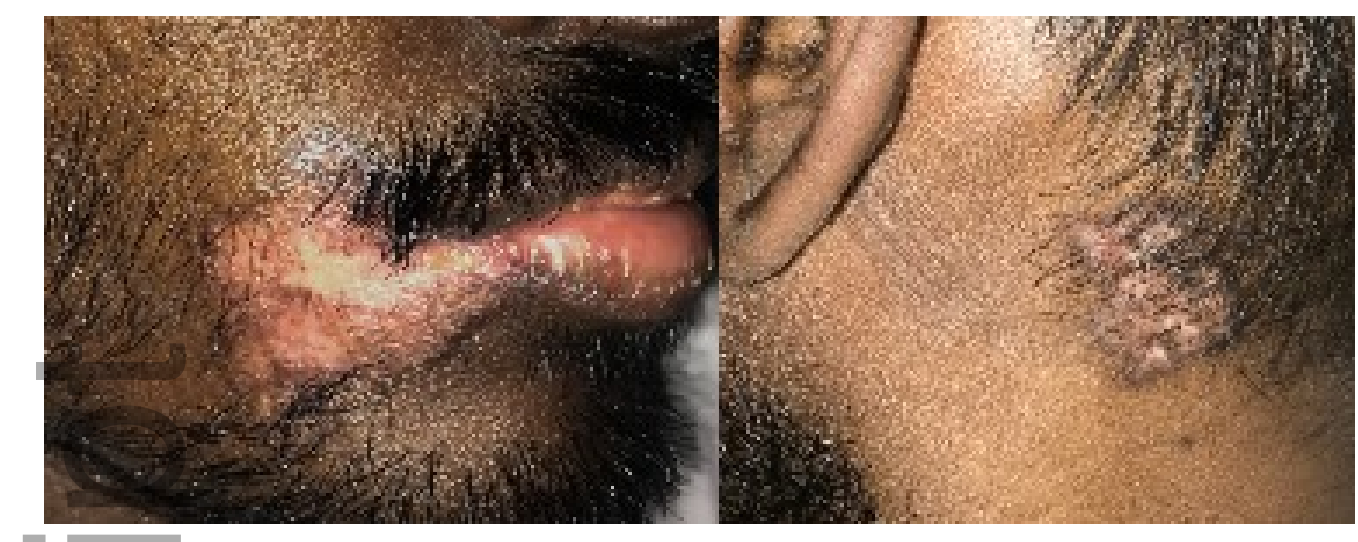

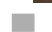

ajd_13111_f3.jpg

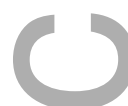

$\infty$
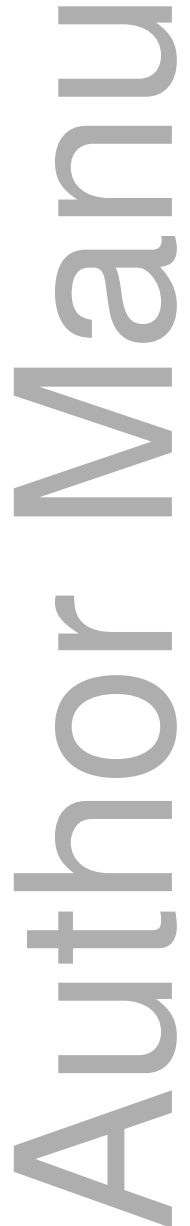

This article is protected by copyright. All rights reserved 


\section{University Library}

\section{- M I I N E R VA \\ A gateway to Melbourne's research publications}

Minerva Access is the Institutional Repository of The University of Melbourne

Author/s:

Howard, MD;Poon, F;Milne, OJ;Kelmann, A;Chong, AH

Title:

Atypical severe progressive perioral ulceration due to herpes simplex virus on the background of undiagnosed HIV/AIDS.

Date:

2020-02

Citation:

Howard, M. D., Poon, F., Milne, O. J., Kelmann, A. \& Chong, A. H. (2020). Atypical severe progressive perioral ulceration due to herpes simplex virus on the background of undiagnosed HIV/AIDS.. Australas J Dermatol, 61 (1), pp.e79-e81. https://doi.org/10.1111/ ajd. 13111.

Persistent Link:

http://hdl.handle.net/11343/286111 